\title{
A national strategy introducing educational computing in primary schools in Chile
}

\author{
M.I. Alvarez \\ La Frontera University \\ Temuco \\ Chile
}

\begin{abstract}
This paper presents the national strategy adopted in Chile since 1990 to introduce educational computing into the primary level as part of a wider programme for improvement of quality and equity in the primary educational system. It analyzes the main issues and some findings from between 1991 and 1994. Preliminary findings suggest that students in some grades have more benefits than those in other grades with respect to selected educational and psychological variables. Interesting communicational relationships arise from the analysis of 'trafficgrammes' a sort of sociogrammes for traffic rates among nodes.
\end{abstract}

Main conference themes: developing countries, infrastructure

Educational areas: elementary education, primary education Study topics:

Secondary keywords: experimental, government, networks, professional development, telecommunications 


\section{INTRODUCTION}

Till the nineties the Chilean educational system has been very centralized. Almost every school in our long and diverse country has the same curriculum, the same school year and the same uninnovative style of teaching. For many decades the Ministry of Education has set up the curriculum of primary schools with few changes. However in the eighties a great change was made: public schools were no longer state schools, but municipal schools and funds were transferred to the municipalities. At the same time a national evaluation system for primary education was implemented which should provide precise global information about achievement levels of every school in the country.

There were no national policies for introducing technology in schools. A few isolated experiments in introducing computing into schools mainly focused on learning programming languages such as Basic or Logo, and computer literacy. These did not have the expected results and showed very high cost in terms of teacher training, laboratories and time spent by teachers and students [1]. However, the need for implementing appropriate strategies at the primary and secondary level was widely recognized by teachers and the Ministry of Education [2]. Because of this computers are now one of the fundamental changes introduced in the national programme for enhancing the quality and equity in education which started at the primary level in 1990. The challenge of this programme is to give to schools responsibility for adapting their teaching practices and curriculum to the student's current life context and the future requirements of society.

\section{Educational innovation mechanisms and computing in school}

Since 1990 the Ministry of Education has developed a programme of about 8 components for the primary level (first to eighth grade). Most of these components are relevant for every primary public school (infrastructure improvement, textbooks for every student, set of books to make a classroom library adapted to the reading level of each grade from first to third grade, carrying out of special training for first grade teachers in health diagnosis to prevent the main health problems, and the like). Two of these components attempt to create mechanisms of innovation inside the school. The first is a contestable fund for local school innovations which as funding mechanism was completely new for schools. It was designed to compel staff of interested schools in reviewing what were the main needs of the schools, their strengths and their weaknesses. The second is a computing pilot project designed to create a computer based network of about 150 schools and other educational institutions, like teacher training institutions and universities, in a wide range of geographical, ethnical, cultural and economical environments. 
The main objective of the computer project for primary schools is to experiment with the integration of telecommunication and multimedia technology in order to provide students and teachers with empowering tools. At the start of the project one question had to be answered: how can we revert the trend of teachers believing that computers are for specialized people and young people, and not useful in everyday activities? The challenge was therefore to integrate telecommunication and multimedia in very easy to use software. Three years of development brought us a user friendly interface for electronic mail and educational software apt for children from 6 to 15 years and their teachers: La Plaza 1.0 [3] which is described in another paper in these proceedings.

At every networked school there is a local network with few computers (2 to 5) with one of them a server connected via dial-up phone lines to the regional Internet site assigned to the school. The La Plaza software has a special feature which makes an automatic call every night to send and receive mail through existing telephone lines, but also sends information about usage of the software for evaluation purposes.

But the software was only one of the issues we had to deal with. There were many other things to think about: how could we involve school staff in the process of introducing computers? what benefits would schools participating in this network obtain? which will be the role of computers in schools? how much support needs the school and of what kind? how can we foster decentralized innovation in school? how can we reduce costs for schools because $80 \%$ of them have no resources? [4].

The Ministry of Education transferred the responsibility of the computer component of the improvement programme to a state university located in a region of the country with a varied population to ensure that the experiment would not be centralized and that the kind of population would represent the diversity of the country.

Table 1 Cumulative information of the school network

\begin{tabular}{lcccc}
\hline Year & Cities & Schools & Teachers & Students \\
\hline 1991 & 1 & 2 & 86 & 1741 \\
1992 & 1 & 6 & 172 & 4224 \\
1993 & 2 & 26 & 641 & 14679 \\
1994 & 14 & 83 & 1513 & 18554 \\
1995 (estimated) & 22 & 350 & 6380 & 78240 \\
\hline
\end{tabular}


Including the two preliminary studies before the beginning of the official project in 1993, Table 1 summarizes the number of cities, schools, teachers and students in the network since 1991 and an estimation for 1995 according to the expansion plan for this year.

\section{School involvement in computer introduction}

The Ministry of Education used to buy the equipment without asking schools what they needed and sent it to them expecting that schools would use this equipment immediately. Much of the equipment is therefore still packed and has never been used. School do not know how to use it neither technically, nor in curricular activities.

The alternative way was making schools compete for a limited quota. This required schools to consider what they were competing for, to prepare a project of what they would like to do with computers and software offered. This strategy has been very useful to create dynamic change inside schools not only for administrative, but also academic staff. The strategy ties in with the other component of the programme, called PME (educational improvement projects with contestable funding).

Once a school has won the right to be in the network the next problem is to ensure that every teacher feels comfortable with computer and software in order to use it with their students as soon as possible. To make this happen we designed a very short hands-on training programme for teachers, both in the use of the interface and in the other tools we provide them with. In Chilean schools there is no IT coordinator and there is no money to have one, so the training had to be enough to make the telecommunication system function and make teachers feel able to use computers. Initially the training was done by university people with groups of at least 15 teachers in the computer room. Now training is similar but with no one from university and based on a selfinstructional software about La Plaza 1.0 and supported by telecommunication. Teachers must do their training tasks using the different software tools, writing messages to other schools in the network to practice basic skills and build links with other teachers all over the country.

The question of how students do learn to use the software is of no interest because they learn it by their own. Teachers are amazed about the learning speed of their students: many of the students which they considered of low learning ability, were able to learn very fast in a setting of computers and group activities.

Teacher training is only the first step in computer introduction in schools. Next initiatives have to be supported and problems resolved. For this there is a team which is periodically meeting with principals and project leaders of every school. 
To know what is happening in every school there is a monitoring system which stores information about messages sent by the school, use of different elements of the software, connections with the server, and the like. Every school can receive graphics of communication traffic of their school, communication relations between schools of the same town, participation in telecommunication projects, etc.

Also institutions for undergraduate teacher training were made aware of the changes of the school system to adapt their own curriculum to the future needs. To accomplish this important requirement we are incorporating new universities as intermediate nodes in the network which are as regional universities then in charge of selecting and supporting the schools. These universities are free in their support tot the schools. One of them has a software developing centre, but most of them have no computer science department, so the kind of support they can give is focused on empowering teachers in using La Plaza.

Some of these universities prepare teachers for rural education, in isolated schools, with just one or two teachers and students of different grades together in the same classroom. Most of them are native people speaking the local dialect instead of Spanish. The changes which telecommunication and computing can bring about in these schools, are yet unknown. We hope that teachers and students will feel less isolated and will feel a sense of power which will make them want to profit from these new tools at school.

\section{Mechanisms of evaluation}

Public schools receive three computers with multimedia, local network and remote network capabilities. Intermediate server nodes have been installed. The Educational Computing Centre which develops the software for schools, represents such an investment by the Chilean government that a sound evaluation is in order to decide on the cost-benefit relation before the current project of 150 schools is expanded to every primary school in Chile $(9600$ schools). The evaluation consists of seven parts:

- The impact of computer introduction in terms of achievement of the main objectives of the curriculum. We will use the national evaluation system already existing to measure changes in academic variables.

- Psychological variables of the students which are expected to change with this way of introducing computers in school. The variables considered are: creativity (fluency, flexibility and originality of the products), perception about the school and perceptions about the teachers, cognitive development levels, social relationships and academic self-consciousness. All of these variables are measured by the Educational Computing Centre and the 
intermediate nodes with existing tests for Chilean population or tests specially developed by our team. Because this is a five year project we can make a follow-up over the students and teachers involved in the pilot network.

- Changes in teachers in the following variables: leadership, self-esteem, achievement, motivation and perceptions about the school, the students and their parents, and personal disposition towards change and innovation.

- Changes in parents and guardians in the following aspects: perceptions about the school, perception about the teachers, perception and commitment to their children's school experiences.

- Traffic levels and software use over time and related to the variables mentioned above. We are also going to evaluate the relation of traffic levels to the growing of the network (number of schools and other institutions involved) [5].

- Communication relationships with an adapted sociogramme where the unit of analysis is every school of a town. This kind of analysis can show either leader schools or isolated ones. It can also show the communications in a subnetwork constituted by a town and the relations among subnetworks.

- Telecommunication project generation inside the schools, level of project participation and level of software use for academic or professional purposes.

\section{Some interesting results}

The follow-up study is just beginning, but we have to date some interesting preliminary results.

The academic achievement assessment depends on the national measurement done every year to eighth and fourth grades alternatively. We therefore have to wait two years to have the second measurement for these grades. The advantage of using this method is that we can evaluate the whole population of fourth and eighth graders of the schools involved in the network.

In addition the sample of students evaluated in reading comprehension comes from the students directly involved in computer activities. We select reading comprehension as a major ability because it is required in many subject areas and is a basic skill on entering secondary education. The comparison of average scores by grade a year after the introduction of computers (1993/1994) gives meaningful differences in second, third, fourth and sixth grades, but only for second grade students the level of reading comprehension is higher in 1994; the others show lower scores in 1994 than in $1993(\mathrm{p}<0.01)$.

Nevertheless, the comparison of the same students in a pre-post study reveals improvement in reading comprehension only in sixth grade and 
deterioration in fifth grade $(\mathrm{p}<0.01)$. The follow-up study will allow us to understand better these results in a long term sense.

Using Piaget's tests in the cognitive development evaluation we found an increase in cognitive level only in fourth grade students $(\mathrm{p}<0.01)$.

On the other hand shows the evaluation of creativity of students a meaningful change in second grade students where fluency decreased and originality increased $(p<0.01)$. There are many explanations for these results. Considering the age of second grade students one of them is a better management of impulsivity because there are less responses in the creativity test, but of better quality.

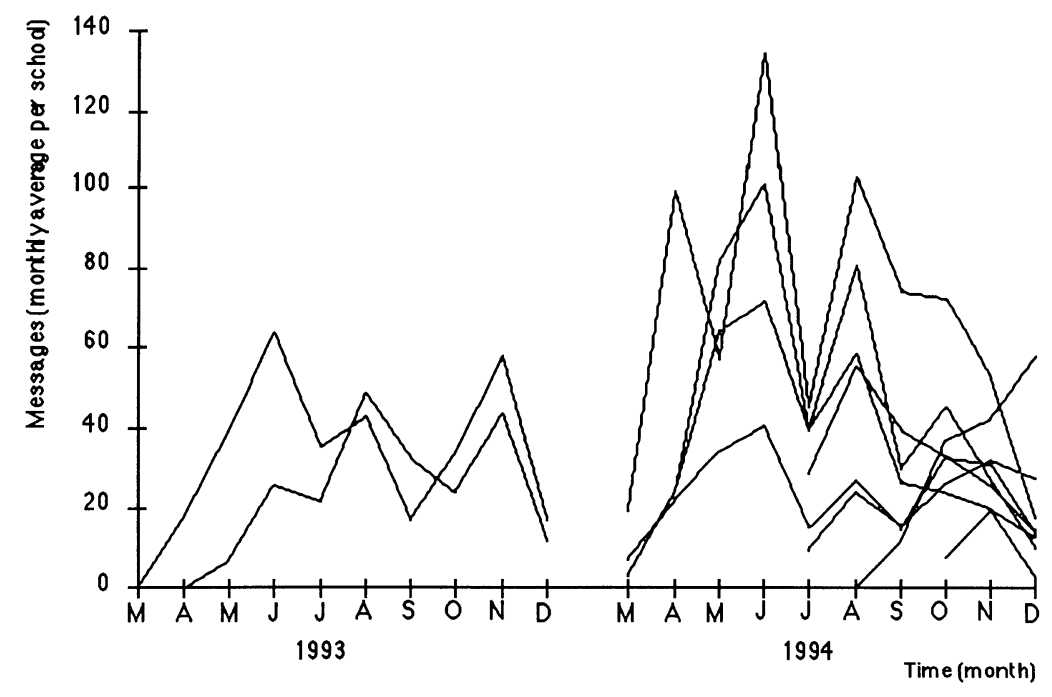

Fig. 1 Average e-mail messages sent per school by subnetwork. January and February not in figure because of summer holidays. Heavy lines are older subnetworks, the continuous heavy line is the subnetwork that started in 1992 (no records available for that year)

Getting results from big samples, geographically distributed, is a slow process especially when some of the evaluations are very specialized and carried out individually. This makes the monitoring system so valuable which only depends on the connection rate of the schools to their server to get current information.

As an example of the kind of information we can obtain from this monitoring system we have a graph of the traffic (based on the number of messages written by each node) related to different variables. The graph allows us to know the behaviour of subnetworks along the year. The oldest subnetwork (heavy continuous line) is slowing down its e-mail activity. The 
productivity of subnetworks which started at the beginning of the school year, is higher than the productivity of subnetworks starting in the middle of the school year (lines beginning in March vs. lines beginning after July). The behaviour of traffic in subnetworks needs a deep analysis to understand the relation between the main trends and other variables like training systems, technical and pedagogical support, selection mechanisms of schools. This kind of graph can be made by day of the week, hour of the day, city, age of nodes.

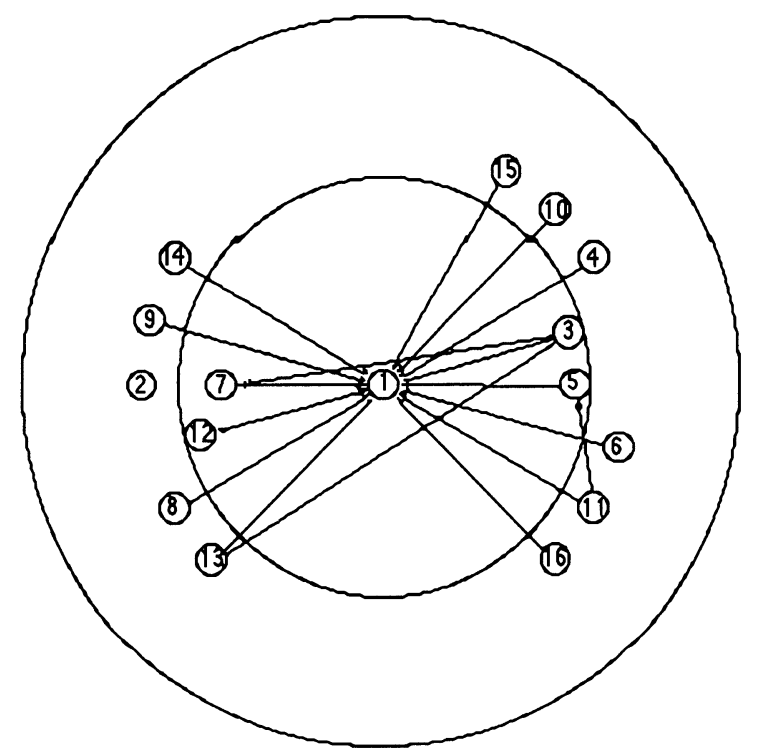

Fig. 2 Traffic relationships of nodes in one city from March to December 1993. Heavy lines are bidirectional preferences, hair lines are unidirectional relationships. Node one is a university node, others are school nodes. Area between both concentric circles is the 'normal zone'

The information about origin and destination of e-mail messages sent by schools can be analized using an analogy with sociometric measures. We can study the relations of preferences among nodes, thus detecting isolated nodes, leaders and dynamic changes of communication behaviour of nodes. The following graph shows the trafficgramme (a sociogramme for traffic relationships) for all the nodes of a city in three different periods of time. Each node is represented by a little circle, all of these are school nodes except node 1 which is the university node.

Ignoring the university node the first year of this subnetwork shows only three unidirectional relations between schools in Figure 2. 


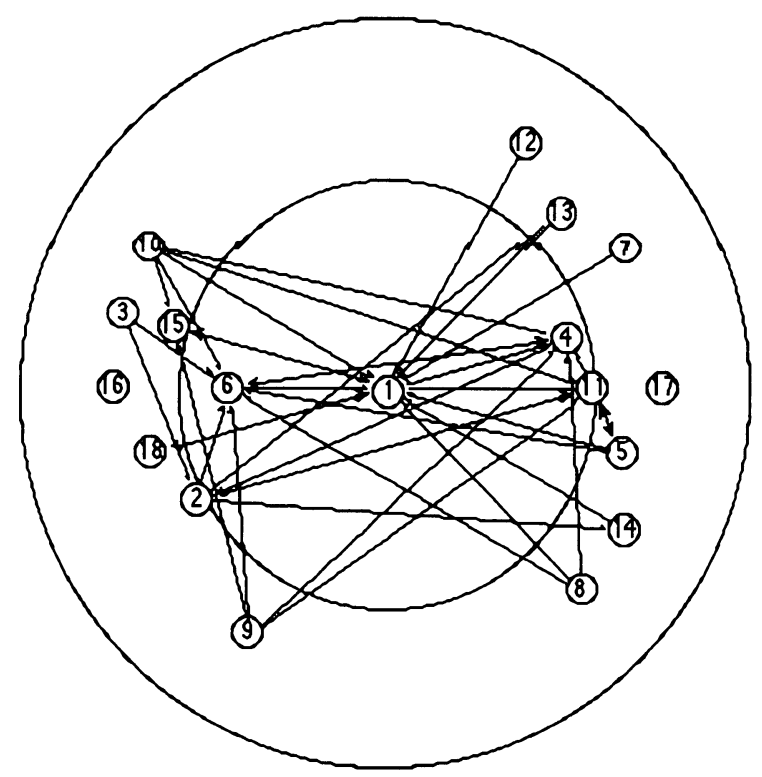

Fig. 3 Traffic relationships of nodes in one city (same as fig. 2) from March to July 1994

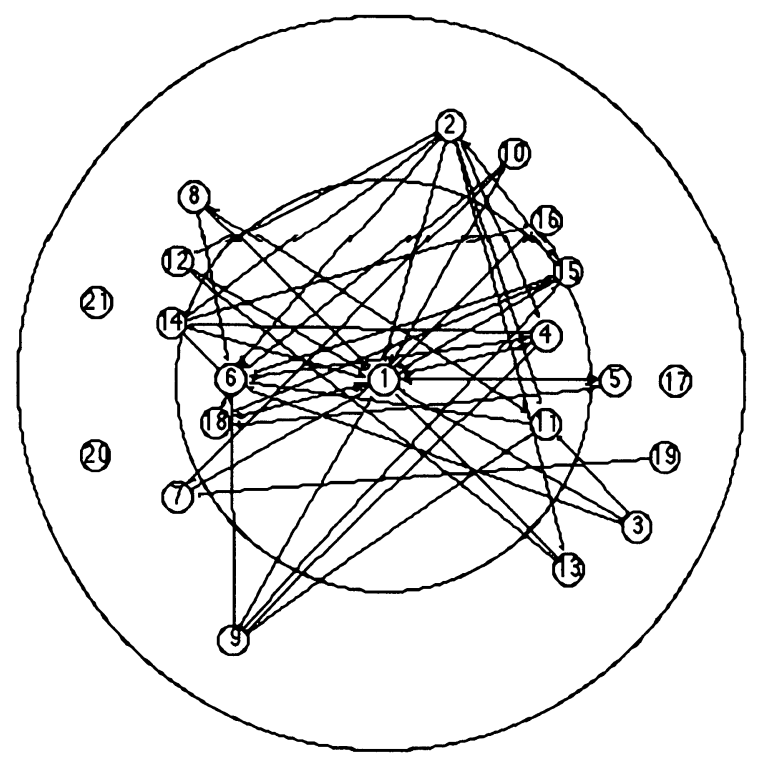

Fig. 4 Traffic relationships of nodes in one city (same as fig. 3) from August to December 1994 
But during the first half of the next year (Fig. 3) appear several unidirectional relationships between schools and some bidirectional relationships. Some schools are preferred for e-mail communication (like node 4 and 6) and others had diversified schools to communicate with (like node 9 and 10). Node 2 which had no meaningful relationships to other nodes in 1993, has shown several meaningful relationships in the second trafficgramme in both ways (as a preferred node and preferring some other nodes). Heavy lines show the emergence of three bidirectional relationships between pairs of schools.

The last graph (Fig. 4) shows an increased number of bidirectional relationships, reflecting the evolution of communication relationships after a year and a half of e-mail activity. Nodes out of the outer circle would be isolated nodes; for these a review is needed to establish the conditions for successful instead of failure.

\section{REFERENCES}

1. Sánchez, J. (1991) Educational computing in Chile: trends, issues and recommendations. Educational Technology, 31 (3) pp. 54-6.

2. Otéza, F. (1993) The impact of computer technology on schools in Chile. Educational Technology, 33 (9) pp. 25-31.

3. Hepp, P., Alvarez, M. I., Hinostroza, E. and Laval, E. (1993) 'La Plaza': A software design for an educational network. Proceedings of ED-MEDIA 93. World Conference on Educational Multimedia and Hypermedia, Orlando, Florida, USA.

4. Alvarez, M. I. (1994) An emerging national school network. Paper presented at the 8th Conference of European School Project. Amsterdam, The Netherlands.

5. Hepp, P., Laval, E., Moenne, G. and Ripoll, M. (1994) Monitoreo y análisis de tráfico en una red educacional. Paper presented at the II Iberoamerican Congress of Educational Computing, Lisbon, Portugal. 